\title{
Fiziksel Engelli Bireylerin Erişilebilirlik Problemi İçin Ăg Analizi: Hacettepe Üniversitesi Beytepe Kampüsü Örneği
}

\author{
Zeynep SÖNMEZ1 ${ }^{1}$, Cevdet Coşkun AYDIN ${ }^{1 *}$ \\ ${ }^{1}$ Hacettepe Üniversitesi, Mühendislik Fakültesi, Geomatik Mühendisliği Bölümü, Ankara \\ (zeynep.sonmez@ @acettepe.edu.tr) ORCID ID 0000-0002-8487-0980 \\ ${ }^{1}$ Hacettepe Üniversitesi, Mühendislik Fakültesi, Geomatik Mühendisliği Bölümü, Ankara \\ (ceaydin@ hacettepe.edu.tr) ORCID ID 0000 - 0003 - 2064-6936
}

\begin{abstract}
$\ddot{O} \mathbf{z}$
Engelli bireylerin şehir hayatında kolay ve rahat ulaşımlarının sağlanabilmesi için hem ülkemizde hem de dünyada resmi ve özel sektör tarafından çeşitli çalışmalar yapılmaktadır. Bu çalışmaların sonucunda yeni yerleşim yerlerinin planlanmasında dikkate alınacak birçok kriter geliştirilmiştir. Bu projede Hacettepe Üniversitesi Beytepe Kampüsü’nde okuyan fiziksel engelli öğrenciler için bu kriterler kapsamında bir ağ analiz çalışması yapılmıştır. Bu çalışma ile Coğrafi Bilgi Sistemleri teknolojileri kullanılarak engelli bireyler için kampüsün mevcut durumu, dikkat edilmesi gereken kriterler açısından incelenmiş ve bu kriterlere nasıl bir katkı sağlanacağı değerlendirilmiştir. Bu değerlendirme ile bireylerin kampüse ulaşımlarında kullanabilecekleri değişik yolların belirlenmesi ile ilgili çeşitli senaryoların üretilmesi amaçlanmıştır. Projede ArcGIS ağ analiz metodu kullanılarak Beytepe Alışveriş Merkezi otobüs durağı ile Hukuk Fakültesi durakları arasında Geomatik Mühendisliği'ne uğranılması şartıyla yol analizleri yapılmıştır. Çeşitli senaryolar değerlendirilerek yeni yol analizleri eklenmiş ve son olarak ArcGIS Server ile kullanıcılara web ortamında sunumu için model oluşturulmuştur. Çalışmanın sonucunda Hacettepe Üniversitesi Beytepe Kampüsü'nün kaldırım, yol ve ulaşım tasarımının fiziksel engelli bireyler için çok uygun olmadığı kanaatine varılmıştır.
\end{abstract}

Anahtar Kelimeler: Fiziksel Engelli Birey, Erişilebilirlik, Coğrafi Bilgi Sistemleri, Ă̆ Analizi, Hacettepe Üniversitesi.

\section{Network Analysis for Accessibility Problems of Individuals with Physical Disabilities: Hacettepe University Beytepe Campus Case}

\begin{abstract}
In order to provide easy and convenient transportation of disabled people in city life, studies are carried out both in the world countries and in Turkey both private and public agencies. As a result of these studies, many criteria have been developed to be considered in planning new settlements. In this project, a network analysis study was carried out for the physically disabled students studying at Hacettepe University Beytepe Campus. With this study, the current situation of the campus for disabled people using Geographical Information Systems technologies has been examined in terms of criteria to be considered and how to contribute to these criteria are evaluated. With this evaluation, it is aimed to produce various scenarios related to the determination of the different ways individuals can use in their transportation to the campus. In the project, road analyzes were performed by using ArcGIS network analysis method, provided that the Beytepe Shopping Center bus stop and the Faculty of Law were visited by Geomatics Engineering. Various scenarios have been evaluated and new path analyzes have been added and finally, ArcGIS Server has been modeled for users on the web. At the end of the study it has been concluded that the pavement, road and transportation design of Hacettepe University Beytepe campus is not very suitable for physically disabled individuals.
\end{abstract}

Keywords: The Physically Handicapped Person, Accessibility, Geographic Information System, Network Analysis,Hacettepe University

\footnotetext{
* Sorumlu Yazar
} 


\section{GÍRIS}

21. yüzyılın önemli küresel eğilimlerinden biri şehirleşmedir. Dünya Bankası verilerine göre 2050 y1lına gelindiğinde dünyadaki 100 kişiden yaklaşık 70' inin şehirlerde yaşaması öngörülmektedir (URL-1). Bunlardan engelli insanların da yüzde 15'inin (yaklaşık 6,25 milyar kişi) 2050 yılına kadar kent merkezlerinde yaşıyor olacağı tahmin edilmektedir (URL-2). Şehirleşmenin yanında erişilebilirliğe olan ilgi artmış ve tüm insanların topluma katılımı için eşit firsatların oluşturulması fikri Türkiye ve dünya kamuoyunda sıkça tartışılır duruma gelmiştir. Çevre faktörlerinin yanı sıra erişilebilirliği, kişi ve çevre arasındaki ilişki olarak incelemek, bireyin bağımsız yaşam derecesini belirlemede ve toplumdaki engelli insanların durumunu tanımlamada önem kazanmaktadır (Iwarsson vd. 2009). Ülkelerin ya da şehirlerin sosyal hayattaki gelişmişliklerinin en önemli kıstaslarından biri de engelli bireylerin günlük hayatlarındaki aktivitelerinde başkalarına mümkün olduğu kadar az ihtiyaç duymalarıdır. (URL-3).

Engelli sayısındaki artış dolayısıyla bir çok ülkede engelli bireylerin refah içinde hayatlarını sürdürebilmeleri için uluslararası kuruluşlar ve organizasyonlarla birlikte kent ölçeğinde, kapsayıcı bakış açılarıyla hedefler belirlenip planlamalar yapılmaktadır. Birleşmiş Milletler'in Sürdürülebilir Kalkınma için 2030 Gündemi kapsamında Dünya'yı Dönüştüren 17 Hedefi 'nden biri olan 11. Hedefi, sürdürülebilir şehirler ve yaşam alanlarıdır. $\mathrm{Bu}$ hedefle kentlerin ve yerleşim yerlerinin bütüncül, güvenli ve sürdürülebilir olması amaçlanmaktadır (URL-4). Ekim 2016'da Ekvador Quito'da Birleşmiş Milletler Konut ve Sürdürülebilir Kentsel Gelişme Konferansi'nda - Habitat III üye ülkeler arasında sürdürülebilir kentsel gelişmede küresel standartları belirleyen, şehirler inşa etme, yönetme ve yaşama biçimimizi yeniden düşünen eylem odaklı bir belge olan "Yeni Kentsel Gündemi (New Urban Agenta)" imzalanmıştır (URL-5). $\mathrm{Bu}$ gündemin önemli bölümlerinden biri olan "Kito Deklarasyonu: Herkes için Sürdürülebilir Kentler ve İnsan Yerleşimleri” nde sürdürülebilir kentsel gelişmeyi hem zorluklar hem de firsatlar açısından ele alıp, planlama, tasarım, finansman, kalkınma ve yönetişim boyutlarında bütüncül bir yaklaşım ile sürdürülebilirliğin gerçekleştirilmesini taahhüt altına almaktadır (URL-6). Bu belge, diğer hedeflerinin yanında 11 'nci Hedefi de merkezine alarak, 2030 Gündemi ile bağlantısını vurgulamaktadır (URL-7).

$\mathrm{Bu}$ düzenlemelere ek olarak dünyada ve ülkemizde de konu ile ilgili çalışmalar yapılmaktadır. Dünyanın değişik ülkelerindeki çalışmalar değerlendirildiğinde; Sze vd. (2017) çalışmasında, Birleşik Devletler, Birleşik Krallık ve Hong Kong'taki ulaşım olanaklarına erişilebilirlikle ilgili herkese, özellikle yaşlilara, görme bozukluğu, işitme zorluğu ve hareket kısıtı gibi farklı engeli olan bireylerin ihtiyaçlarını karşılayabilecek, erişilebilir tasarım uygulamaları önerilmiştir. Gray vd. (2012), "yapılı çevre" kavramı tanımı altında, bireyin fiziksel olarak aktif olma kabiliyetini kolaylaştıracak veya engelleyebilecek insan yapılarına (ör. Kentsel ve kırsal tasarım özellikleri, eğlence yapıları) işaret edip engellilik ve evrensel tasarım ile alakalı olarak yürüyebilirlik, bisiklet kullanabilirlik ve rekrasyon ölçen 95 araç üzerinde bir içerik analizi yapmıştır. Schlingensiepen vd. (2015) tarafından Almanya 'da yapılan bir çalışmada ise "the project mobile" ile engellilere, kamusal olmayan alanlarda kendilerine gerekli araçların sağlanması amaçlanmıştır. Ferrari vd. (2013), Londra'da engelli insanlara erişilebilirliği ölçmek için, ağ ve uzay-zaman analizine dayalı genel bir metodoloji sunmuştur. Bashiti ve Rahim (2016), Litvanya'nın Vilanus şehri için yapılan bir çalışma ile hareket engeli olan insanlar için toplu taşıma araçlarının değerlendirilmesi ve mevcut toplu taşıma hizmetlerini iyileştirmek için önerilerde bulunulmuştur. Mikusova (2014)'ün projesinde, toplu taşıma araçlarının ve kamusal alanın erişilebilirliği ile ilgili politika denetimleri ve kalite yönetim planları üzerinde durulmuş bu konu ile ilgili yapılan çalışmalar mevcut sorunlar ile beraber 
değerlendirilmiştir. Konu hakkında uluslararası standart geliştirme kuruluşlarının standartlarının da değerlendirildiği engelli bireyler için "kamu taşımacıllığının ve kamusal alanın erişilebilirliğine ilişkin" kapsamlı bir genel bakış sunmayı amaçlayan çalışmalar yapılmış ve ISO 9 000, ISO 14 000, EMAS ve EFQM modelleri değerlendirilmiştir.

Fiziksel engelli bireyler için günümüzde hemen hemen her alanda kullanılan coğrafi bilgi sistemleri ile de bazı çalışmalar yapılmış ve yapilmaya devam etmektedir. Sedlak vd. (2010), Çekya'nın Pardubice șehrinde fiziksel engelli insanlar için kent ortamındaki engeller coğrafi bilgi sistemlerindeki uygun analizlerle belirlenip öneriler sunulmuştur. Aynı şekilde Enders ve Brandt (2007) çalışmalarında, engelli insanların acil durum ve felaketlerde erişimlerinin sağlanmasında coğrafi bilgi sistemi teknolojilerinin kullanılmasını önermişlerdir.

Ülkemizde de konu ile ilgili değerli çalışmalar yapılmakta, engelli bireylerin değişik uygulama alanlarında yaşadıkları sorunlar gündemde tutulmaya çalışılmaktadır. Ayrıca bu sorunların giderilebilmesi için tespitler ve tavsiyeler sunulmaktadır (Kurtaş vd. 2017, Esatbeyoğlu vd. 2014). Öztürk ve İsmail (2015), fiziksel engelli kullanıcıların Kastamonu kent merkezi Kışla Parkı'na ulaşımlarında yaşadıkları engellerini ve bölgedeki eksikliklerini birkaç farklı medya arac1 ile tespit etmişlerdir. Sirel vd. (2012) Çukurova Üniversitesi'nde, Çivici ve Gönen (2015) Balıkesir Üniversitesi'nde ve Özkan ve Y1lmaz (2015) Hacettepe Üniversitesi'nde yaptıkları çalışmalarda engelli bireylerin erişimleri konusunu merkeze alıp, bu konu ile ilgili standartlar çerçevesinde değerlendirmeler yapmışlardır. True ve Türel (2013), tarafinda yapılan çalışmada ise İzmir ili merkez ilçelerinde, yapılı mekânlar ile bu mekânlara erişimde önemli rol oynayan erişim bileşenleri, engelli kullanıcıların görüşleri doğrultusunda değerlendirilmiştir. Eliöz vd. (2017), On Dokuz Mayis Üniversitesi'nde yapılan çalışmada ise Türkiye'deki 81 ili kapsayan, engelliler için kritik öneme sahip, toplumsal hayata katılımlarını sağlamada sağlık, ekonomi, eğitim ve yaşam kalitesi gibi kategorilerde Engelli Dostu İller Siralamas1 oluşturulmuştur. Tellioğlu ve Şimşek (2016),
“Dünyada ve Türkiye'de Engelli Dostu Turizm" adlı çalışmalarında engelli insanların turistik bölgelere ulaşımları ve bu bölgelerdeki yapılı çevrenin yasal çerçevede olması gereken standartları üzerinden değerlendirmeler yapmışlardır.

$\mathrm{Bu}$ çalışmada ülkemizde ve dünyada engelli bireylerin yaşadıkları sorunlar hakkında mevcut durum değerlendirilmesi yapılmış, buna ek olarak, Hacettepe Üniversitesi Beytepe Kampüsü'nün bir bölümünde fiziksel engelli bireyler için bir ağ uygunluk analizi çalışması gerçekleştirilmiştir. Mevcut yap1, kriterler çerçevesinde değerlendirilmiş ve elde edilen bulgular, sonuçlar, eksiklikler ve öneriler çalışmaya eklenmiştir. Bu çalışma ile engelli bireylerle ilgili kent yaşamındaki kriterlerin gerçekliliğinin sorgulanması, bu konudaki CBS teknolojileri ile harita tabanlı uygulamaların eksikliğine dikkat çekilmesi ve bu konunun ülkemizdeki farkındalığının arttırılması gibi bilimsel katkılar sağlanması amaçlanmıştır.

\section{ENGELLİ, ERİŞEBİLIRLİK VE AĞ ANALIZI}

\subsection{Engelli}

Birleşmiş Milletler'de kabul edilen engelli birey hakkındaki tanımlama ifadesi, "Engelli Kişilerin Hakları Bildirgesi"nde, "Normal bir kişinin kişisel ya da sosyal hayatında kendi kendisine yapması gereken işleri, bedeni veya ruhi yeteneklerindeki kalıtımsal ya da sonradan olma herhangi bir noksanlik sonucunda yapamamasıdır." şeklinde yapılmaktadır.

Dünya Sağlık Örgütü, engeliliği, engellilerin sağlıklarını dikkate alarak tanımlamaktadır: Engellilik (Disability): "Sağlık alanında bir noksanlık sonucu meydana gelen ve normal sayılabilecek bir insana oranla bir işi yapabilme yeteneğinin kaybedilmesi ve kisitlanması durumunu ifade eder." (URL-8).

Ülkemizde 7 Temmuz 2005 tarihinde yayımlanarak yürürlüğe giren 5378 sayılı Engelliler yasasında ise engelli birey; ruhi, fiziki ve zihni melekelerindeki kayıplardan dolayı toplum hayatına diğer sağlıklı bireyler gibi eşit şartlarda katılımlarını kısıtlayan davranış ve çeşitli fiziki çevre şartlarından etkilenen kişi olarak tanımlanmıştır (Tandoğan, 2017). 


\subsection{Erișilebilirlik}

Aynı yasada Erişilebilirlik kavramı da şöyle tanımlanmaktadır; Erişebilirlik özellikle coğrafya bilimi, kamu yönetimi, şehir planlaması ve ulaşım planlaması gibi alanlardaki çalışmalarda kullanılan ve her geçen gün karar vericiler için önemi artan bir kavramdır. Farklı alanlarda kullanılmasından dolayı erişebilirlik kavramının tek bir tanımı bulunmamaktadır (URL-9). Genel bir tanımlama yapılması gerekirse, erişilebilirlik; farklı ihtiyaçları olan insanların daha serbest bir hayat yaşayabilmeleri, daha geniş alanlara ulaşabilmeleri ve bu alanlardaki imkanları kullanabilmeleri olarak ifade edilmektedir (Kesik vd. 2015). Ayrıca 5378 sayılı Engelliler Hakkında Kanunu'nun 3. Maddesinde Erişilebilirlik; Şehir alanlarının, meskenlerin, ulaşım hizmetlerinin ve iletişim teknolojilerinin engelli bireylerin kullanımına açık ve güvenle ulaşılabilir olması, olarak da ifade edilerek "erişilebilirlik standartları" Türk Standartları Enstitüsü'nün erişilebilirlikle ilgili yayımladığı standartlar olarak tanımlanmıştır (Tandoğan, 2017).

Bireylerin erişilebilirliği şehir alanlarında kendileri için ihtiyaç duyulabilecek, gerek fiziki ve gerekse yapılaşma adına her türlü tedbirin alınması ile yakından ilgilidir. $\mathrm{Bu}$ alanlardaki tedbirler sadece engelli bireylerle ilgi olmayıp yaşlılar, hamile ve çocuklar ve hareket kısıtll1lı̆ 1 yaşayan herkes için geçerlidir (Kesik vd. 2015).

\subsection{A $\breve{g}$ Analizi}

A $\breve{g}$ analizi; vektör tabanlı coğrafi veriler ile gerçekleştirilen, çizgi özelliği gösteren coğrafi verilerle karar-destek amaçlı analizlerdir. A $\breve{g}$ verisinin yönetimi, CBS yazılımlarının yapısına göre farklılık göstermektedir. Örneğin yalnız tek yönde hareketi gerektiren elektrik, doğalgaz ve su gibi çizgisel mühendislik yapıları ile, iki yönde hareketi gerektiren karayolu ve tren yolu gibi ulaşım altyapılarında farklı ağ veri setleri kullanılmaktadır.

Ağ oluşturulurken temel olarak dört adım bulunmaktadır: 1. Veri seti kurulur ve katmanlar belirlenir. 2. Katmanların üstlendiği roller belirlenir, bağlantılar, $\mathrm{Z}$ değerleri, seyahat süresi ve yön gibi öznitelik bilgileri veri setinde tanımlanır. 3. Dönüş bilgileri ağa dâhil edilir. 4. Ağ oluşturulur (Kesik vd. 2015) (Şekil 1).

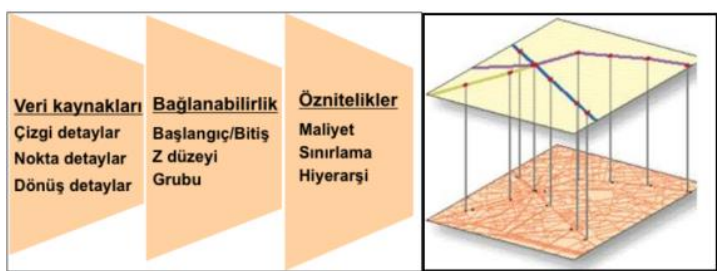

Şekil 1. A $\breve{g}$ Tanımlayıcıları ve Veri Yapısı

Ağ analizinde en önemli problem bir düğüm noktasından diğer düğüm noktasına olan en kısa yolun bulunmasıdır. En kisa yol problemi çok geniş kapsamlı ulaşım problemlerinin çözümünde uygulanmaktadır. $\mathrm{Bu}$ algoritma herhangi bir kaynaktan varılacak yere olan en kısa yolu bulmak amaciyla kullanılmasina rağmen, çözüm karmaşık problemleri çözmek için kaynak noktaların birleştirilmesi ve ara duraklar ile sağlanabilir. Bazı kısıtlayıcı faktörleri de dikkate alarak, alternatif güzergahlar arasında en kısa ulaşım suresine sahip optimum güzergahın belirlenmesinde bilgisayar destekli metotlar kullanılmaktadır. Topoloji ağı oluşturulmuş bir veri setinde A noktası ile B noktası arasında zaman veya mesafe koşuluna göre belirlenen ek kısa mesafeye "rota analizi" denilmektedir (Büke ve Erturaç, 2016).

A $\breve{g}$ analizi günümüzde çok değişik alanlarda kullanılmaktadır. Bu kullanım alanlarından biri de konumsal ağların modellenmesi ve analizidir. Bugün, özellikle günlük hayatımızda ulaşım ağlarının belirlenmesinde, araçların rotalarının çizilmesinde, kent planlamasında ve engelli bireyler için yapılan planlamalarda ağ analizinden etkin bir biçimde faydalanılmaktadır (Şekil 2).

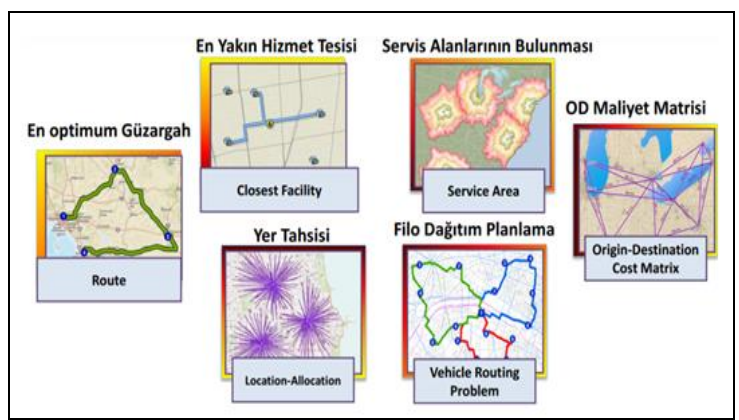

Şekil 2. Ağ Analiz Fonksiyonları (URL-10) 


\section{YÖNTEM}

\section{1. Çalışma Alanı}

Çalışma alanı Ankara'da Hacettepe Üniversitesi'nin Beytepe Yerleşkesi'nde bulunmaktadır. Yerleşke, Ankara'nın güney batısında Ankara-Eskişehir yolunun 20. kilometresinde yaklaşık 600 hektarlık bir alan üzerinde kurulmuştur. Kampüs girişi Ankara Eskişehir yolunun 4 kilometre güneyindedir (Şekil 3). Uygulama alanı Ego Otobüs Durakları'ndan Beytepe Alışveriş Merkezi Durağı, Hukuk Fakültesi Durağı ile Geomatik Mühendisliği Bölümü arasındaki bölge olarak seçilmiştir.

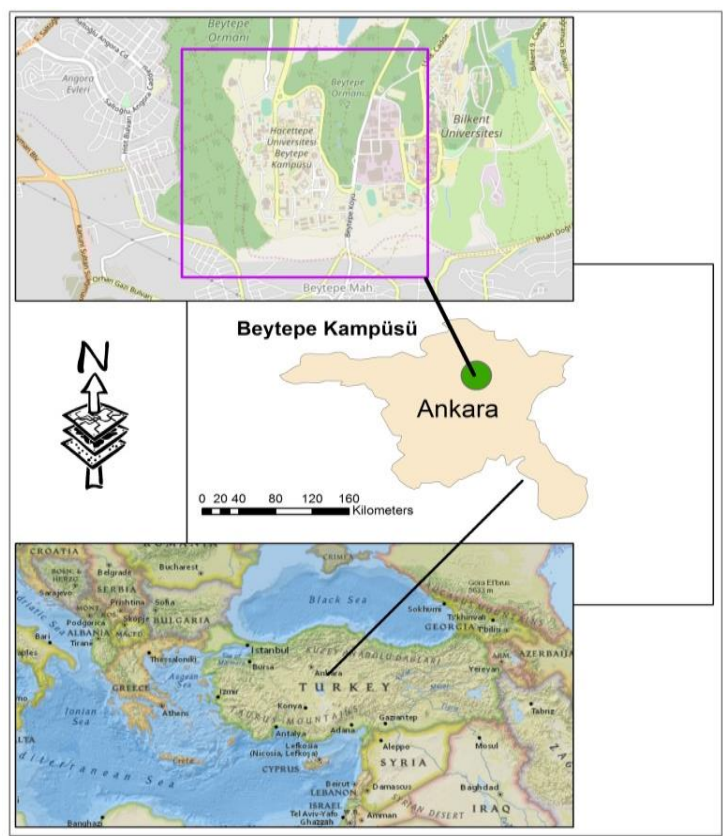

Şekil 3. Uygulama Alanı

\subsection{Mevcut Durum Analizi}

Proje çalışmasına altlık teşkil edecek şekilde uygulama alanına ait mevcut durum analizi yapılmıştır. $\mathrm{Bu}$ analiz esnasında bölgenin sosyal çevresi, donatıları ve uygulamanın gerçekleştirilebilmesi için gerekli haritalar, uydu görüntüleri vb. değerlendirilmiştir (Tablo 1).

Tablo 1. Proje Planlama Aşamaları ve Kullanılan Materyaller

\begin{tabular}{l|l}
\hline \multicolumn{1}{c|}{ Aşama } & \multicolumn{2}{|c}{ Konu ve Uygulama Alanı } \\
\hline & Çalışma alanı için gerekli \\
bilgilerin elde edilmesi, kent \\
Mevcut Durum & yaşamı ç̧in çalışma alanının \\
Analizi & önemi, çevre özellikleri, yap1 \\
& koşulları, bölgedeki kentsel \\
& yapılar. \\
\hline
\end{tabular}

\begin{tabular}{l|l}
\hline $\begin{array}{l}\text { Ölçme } \\
\text { Materyallerinin } \\
\text { Elde Edilmesi }\end{array}$ & $\begin{array}{l}\text { Bölgenin sayısal haritaları, } \\
\text { ortofoto, uydu görüntüleri, yer } \\
\text { kontrol noktaları, yersel } \\
\text { fotoğraflar. }\end{array}$ \\
\hline & $\begin{array}{l}\text { Sayısallaştırma, güzergahların } \\
\text { fotoğraflanması, veri tabanında } \\
\text { Uygulama } \\
\text { bşamasilerin tespit edilmesi, model } \\
\text { tasarımı, gerekli sorgulamaların } \\
\text { yapılması ve ağ analizi }\end{array}$ \\
\hline
\end{tabular}

Öncelikle Geomatik Mühendisliği Binası'na belirli iki duraktan erişimde muhtemel yolların belirlenmesi için bölgede bulunan tüm yollar ve bu yollar üzerinde fiziksel engelli bireylerin ulaşımını olumlu ya da olumsuz etkileyebilecek çevresel faktörler belirlenip fotoğrafları çekilerek mevcut durum analizi yapılmıştır (Şekil 4).
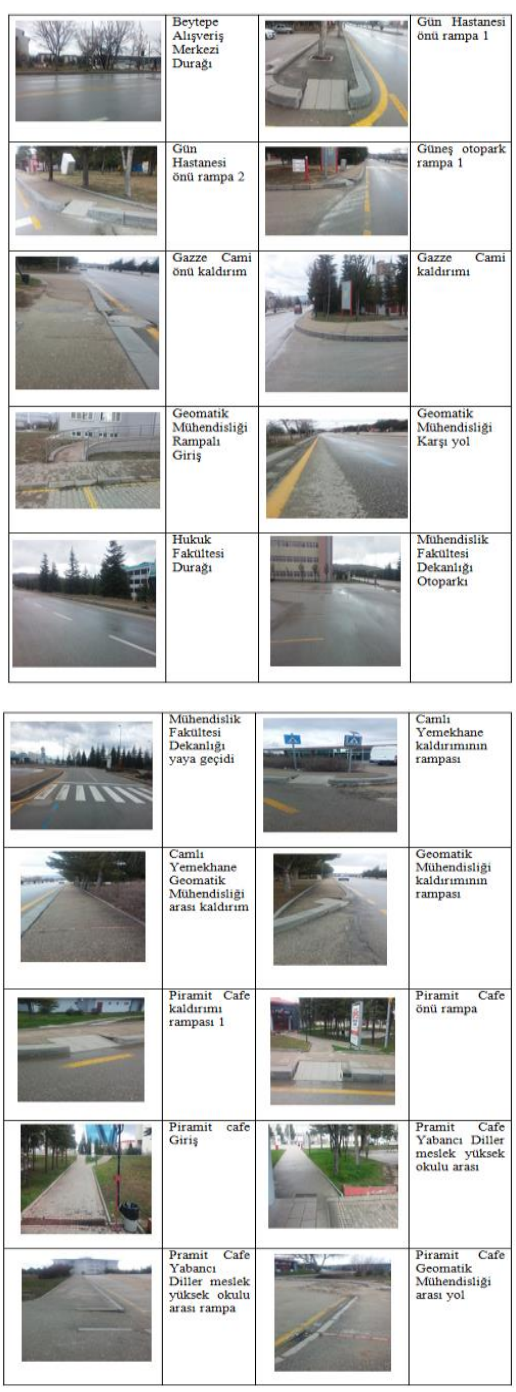

Şekil 4. Uygulama Alanındaki Durum Tespit Çalışmaları 


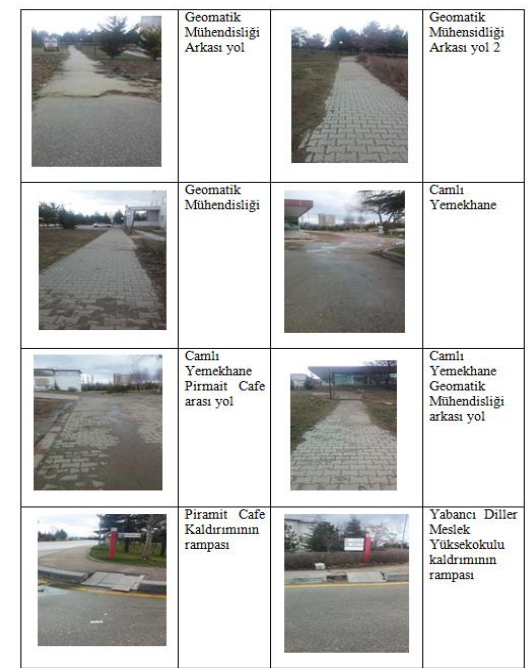

Şekil 4. (devam ediyor) Uygulama Alanındaki Durum Tespit Çalışmaları

\subsection{Sayısallaştırma}

İlgili bölge, temel harita üzerinden ArcMap 10.3 programında bina, kaldırım, arayol, durak, rampa, bina girişi ve orta kaldırım veri setlerinde, poligon, doğru ve nokta özellik sınıflarına ayrılarak sayısallaştırılmıştır (Şekil 5). Koordinat sistemi olarak çalışma alanının Ankara'da olması ve daha önceden bu bölgede yapılan çalışmalarda kullanılacak olan verilerin yerel koordinat sisteminde olmasından dolayı TUREF TM33 seçilmiştir.

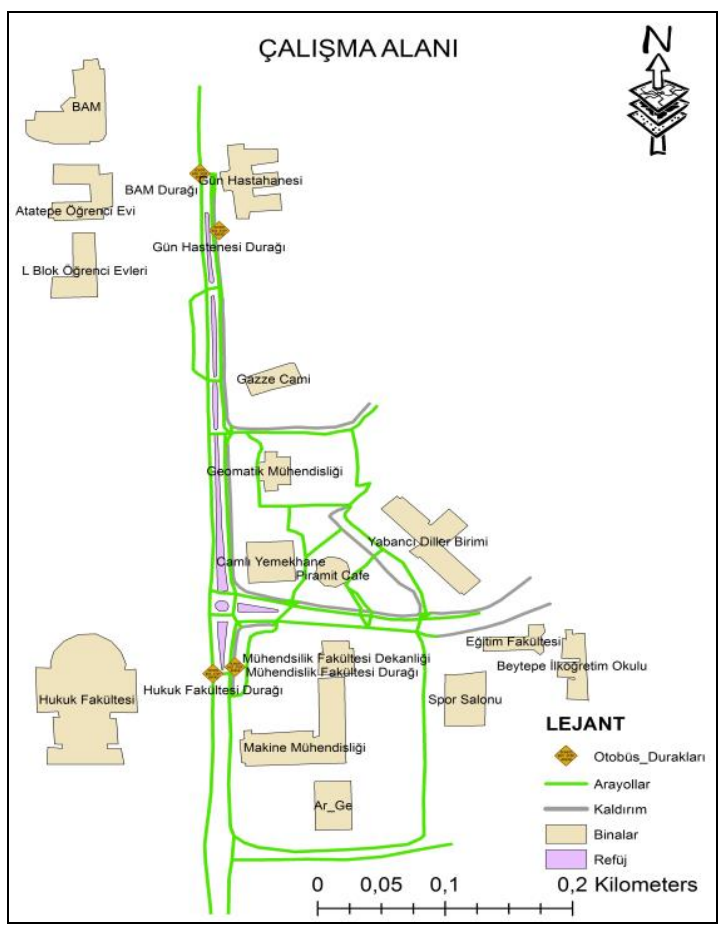

Şekil 5. Çalışma Alanının Öznitelik Sınıfları
Yol, rampa, bina, durak gibi özellik sınıflarının yükseklik ve eğim verilerini elde etmek için çalışma alanında mevcut olan yer kontrol noktalarından TIN formatında bölgenin üçgen modeli, bu model kullanılarak da sayısal yükseklik modeli (SYM) üretilmiştir (Şekil 6).

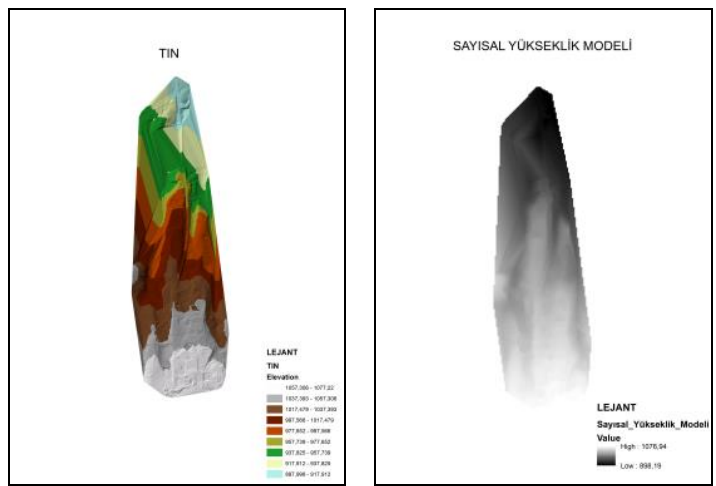

Şekil 6. Çalışma Alanına ait TIN ve SYM Haritaları

Elde edilen değerler veri tabanında mevcut olan öznitelik tablolarına eklenmiştir (Şekil 7).

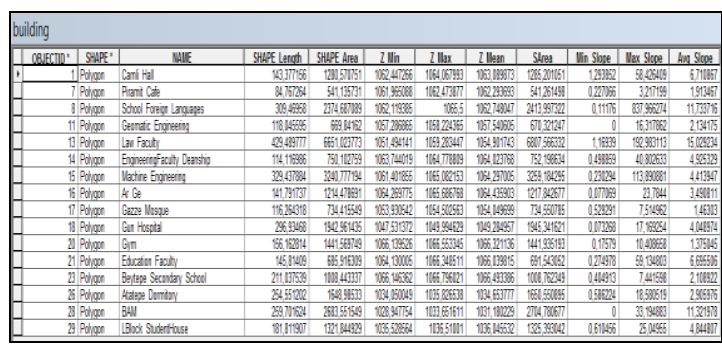

Şekil 7. Poligon Özellik Sınıfı Verileri

\subsection{A $\breve{g}$ Analiz Veri Setinin Olușturulması}

Türk Standartları Enstitüsü'nün Nisan 1999 yılında yürürlüğe kazandırdığı TS 12576 "Şehir içi Yollar-Özürlü ve Yaşlılar için Sokak, Cadde, Meydan ve Yollarda Yapısal Önlemler ve İşaretlemelerin Tasarım Kuralları" na göre (Şekil 8) şehir alanlarında engelli insanların daha rahat hareket edebilmesi için bu kurallara uyulması çok önemlidir. Çalışma alanında bu kurallar çerçevesinde yollarda olması gereken eğim oranı, engelli bireyin ulaşımının güvenliği açısından yol sınıflarına öncelik sırası ve bir akülü engelli aracının saatteki hız miktarına göre ArcMap 10.3 programı Network Analiz Modülü'nde analiz seti oluşturuldu. 


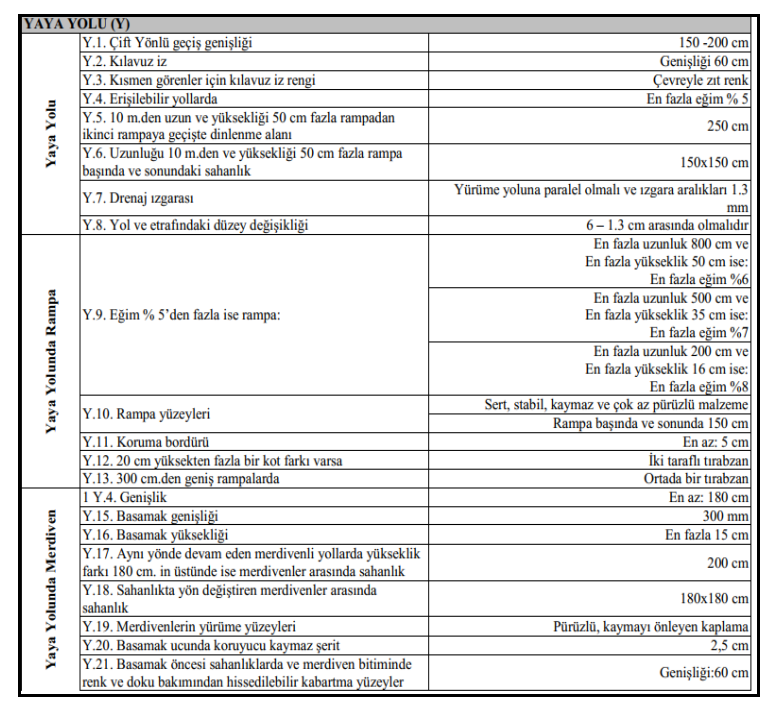

Şekil 8. Veri Seti Tasarım Kuralları

\subsection{Model Olușturulması}

Çalışmanın gerçekleştirildiği ArcGIS yazılımında modelleme modülü olarak "model builder" kullanılmıştır. "Model builder", geoprocessing iş akışlarını oluşturmak için görsel bir programlama dilidir. Geoprocessing modelleri, mekansal analiz ve veri yönetimi süreçlerini otomatik hale getirir ve belgelendirir. Modelin, bir işlemin çıtısısını başka bir işlemin girdisi olarak kullanan süreçlerin ve coğrafi işlem araçlarının zincirlerini bir araya getiren bir şema olarak gösterildiği, "model builder"'de coğrafi işlem modelleri oluşturulup, değiștirilebilir.

"Model builder"'ın faydaları aşağıdaki gibi özetlenebilir:

- "Model builder", bir dizi araç içeren iş akışları oluşturmak ve çalıştırmak için kullanımı kolay bir uygulamadır.

- "Model builder" ile oluşturulan araçlar Python komut dosyasında ve diğer modellerde kullanılabilir.

- "Model builder", komut dosyasi ile birlikte, ArcGIS'i diğer uygulamalarla entegre etmenin bir yoludur (URL-11).

$\mathrm{Bu}$ çalışmada yapılan Ağ Analizi'nin web ortamında kişilerin kullanımına sunulmasında "model builder" kullanılarak bir model tasarımı yapılmıştır (Şekil 9). Bu tasarımda çalışma bölgesinin verktör veri seti kullanılarak bölgedeki ulaşım durakları işaretlendirilmiş ve verilen kriterlere göre istenilen en kısa yollar analiz edilmiştir.

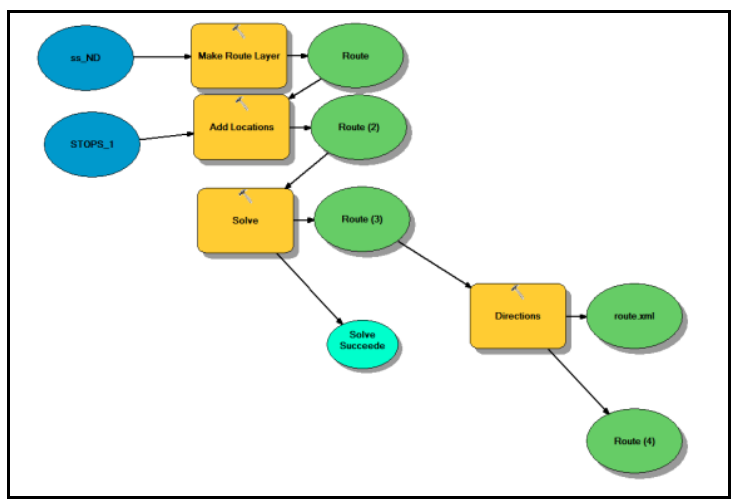

Şekil 9. Çalışma Alanına ait A $\breve{g}$ Analiz Modeli

\section{BULGULAR ve SONUÇLAR}

\subsection{Bulgular}

a)

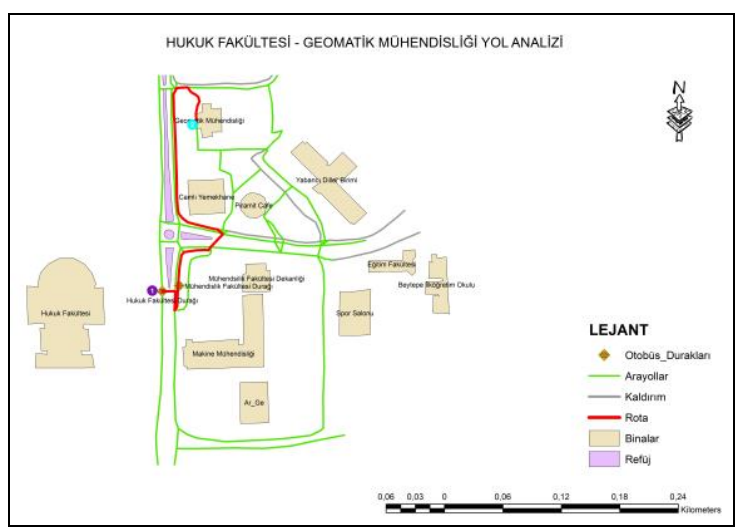

b)

\begin{tabular}{|c|c|c|c|c|c|}
\hline ^ & & Directions (Route) & & $-\square$ & $\mathrm{x}$ \\
\hline$[-1]$ & \multicolumn{2}{|c|}{ Route: Graphic Pick 1 - Graphic Pick 2} & \multirow[t]{2}{*}{$0,2 \mathrm{mi}$} & \multirow{2}{*}{$4 \min$} & \multirow{2}{*}{$\frac{\text { Map }}{\text { Map }}$} \\
\hline & 1: & Start at Graphic Pick 1 & & & \\
\hline & 2: & $\begin{array}{l}\text { Go south on Law_Faculty_1 toward Law_Faculty_2 / } \\
\text { LF_EFD_Passing__ }\end{array}$ & $4 \mathrm{ft}$ & $<1 \mathrm{~min}$ & Map \\
\hline & 3: & $\begin{array}{l}\text { Turn left on LF_EF__Passing_1 and immediately turn right } \\
\text { on EF_Deanship_4 }\end{array}$ & $96 \mathrm{ft}$ & $<1 \min$ & Map \\
\hline & 4: & Continue on 36 & $12 \mathrm{ft}$ & $<1 \min$ & Map \\
\hline & $\underline{5}:$ & Make sharp left on 26 & $14 \mathrm{ft}$ & $<1 \mathrm{~min}$ & Map \\
\hline & 6: & Bear left on Engineering_Faculty_Deanship & $188 \mathrm{ft}$ & $<1 \mathrm{~min}$ & Map \\
\hline & z: & Turn right on 4 & $83 \mathrm{ft}$ & $<1 \mathrm{~min}$ & Map \\
\hline & 8: & Turn left on 34 & $14 \mathrm{ft}$ & $<1 \mathrm{~min}$ & Map \\
\hline & g: & Continue on 25 & $60 \mathrm{ft}$ & $<1 \mathrm{~min}$ & Map \\
\hline & 10: & Turn left on 60 & $22 \mathrm{ft}$ & $<1 \mathrm{~min}$ & Map \\
\hline & 11: & Continue on 5 & $3 \mathrm{ft}$ & $<1 \mathrm{~min}$ & Map \\
\hline & 12: & Bear left on CamliHall_2 & $145 \mathrm{ft}$ & $<1 \mathrm{~min}$ & Map \\
\hline & 13: & Bear right on CamliHall & $390 \mathrm{ft}$ & $1 \mathrm{~min}$ & Map \\
\hline & 14: & Continue on 4 & $5 \mathrm{ft}$ & $<1 \min$ & Map \\
\hline & 15: & Bear right on 58 & $31 \mathrm{ft}$ & $<1 \mathrm{~min}$ & Map \\
\hline & 16: & $\begin{array}{l}\text { Turn right on } 4 \text { and immediately turn right on } \\
\text { Geomatic Engineering } 1\end{array}$ & $103 \mathrm{ft}$ & $<1 \mathrm{~min}$ & Map \\
\hline & 17: & Turn right on Geomatic_Engineering_2 & $83 \mathrm{ft}$ & $<1 \min$ & Map \\
\hline \multirow{2}{*}{\multicolumn{2}{|c|}{ 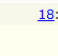 }} & Finish at Graphic Pick 2, on the right & & & Map \\
\hline & & $\begin{array}{l}\text { Total time: } 4 \mathrm{~min} \\
\text { Total distance: } 0,2 \mathrm{mi}\end{array}$ & & & \\
\hline
\end{tabular}

Şekil 10. a) Hukuk Fakültesi ile Geomatik Mühendisliği Yol Analizi Haritas1, b) Yol Tarifi Tablosu 
Oluşturulan ağ setinde, iki ayrı yol analizine göre sonuçlar ve yol tarifleri Şekil 10 ve Şekil 11 ' de gösterilmiştir. $\mathrm{Bu}$ yol analizlerine göre şekil 11'de çizilen rotanın varış süresi şekil 10 'da çizilen rotanın varış süresinden yaklaşık 1 dakika daha az sürmektedir. Ayrıca kaldırım ve arayol yol siniflarından güvenli olan kaldırım yol sinıfının tercih edilmesiyle kısıtlamaya gidilmiş ve sonuç olarak iki ayrı güzergahta da rotalar kaldırım yol sınıfi üzerinden belirlenmiştir.

a)

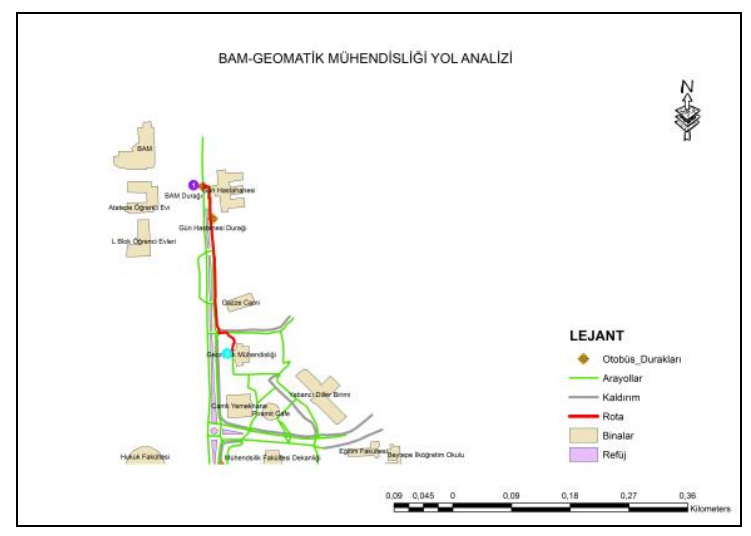

b)

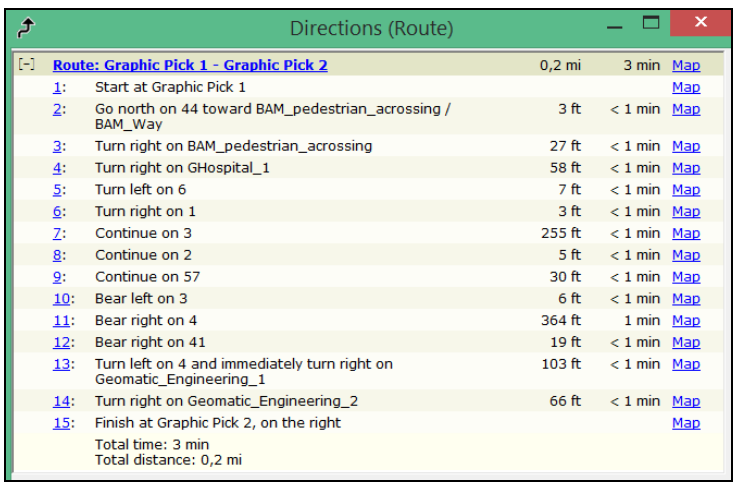

Şekil 11. a) BAM-Geomatik Mühendisliği Yol Analizi Haritas1, b) Yol Tarifi Tablosu

$\mathrm{Bu}$ çalışmada fiziksel engelli bireylerin, yürürlükte olan kıstaslar çerçevesinde erişilebilirliği üzerine bir ağ analiz çalışması gerçekleştirilmiştir. Bu çalışma için Hacettepe Üniversitesi Beytepe kampüsünün ana yol güzergâh1 üzerinde iki ayrı bölge değerlendirilmiştir. Çalışma sırasında karşılaşılan tespitler, eksiklikler ve öneriler ayrı maddeler halinde sunulmuştur. Çalışmanın sonucunda Beytepe Kampüsü'nün anayol güzergâhı üzerindeki açık alanlarının fiziksel engelli bireylerin kullanımına uygun olmadığ tespit edilmekle beraber, bazı değişiklikler, eklemeler ve düzenlemelerle uygun hale getirilmesinin mümkün olabileceği öngörülmüştür. $\mathrm{Bu}$ çalışma kapsamındaki bulgular aşağıda özetlenmiştir;

- Kampüs alanında sadece tek taraflı kaldırımın bulunması ve mevcut kaldırımların çok azında rampa olması,

- Seçilen iki durakta da iniş ve binişler için uygun bir kaldırımın bulunmamas1,

- Rampali kaldırımların bazılarında gidiş yönüne göre kaldırımın başında ya da sonunda rampaların bulunmamas1,

- Bazı rampaların eğimlerinin yönetmeliğe uygun olmaması,

- Kaldırımlı yollarda rampa çıkışlarının hemen yanında ya da yolların ortasında engelli aracının geçişini zorlayıcı ağaç, çöp kutusu ve levhaların bulunmasi,

- Kaldırımın bulunduğu yönde saat 12:00'dan sonra servis araçlarının park etmesi ve sira olmasi sebebiyle buradan geçişin zor olması, buna mukabil alternatif yolların güvenilir olmamas1,

- Alternatif yolların fiziksel engelli araçlar için uygun eğim değerlerine sahip olmamas1,

- Geomatik Mühendisliği binasının bulunduğu bahçeye engelli kişinin akülü aracı için uygun sadece tek girişin olması ve bu girişin bulunduğu yerde araçların park alanı olması,

\subsection{Sonuçlar ve Öneriler}

- Ülkemizde fiziksel engelli bireyler için yapılmış herhangi bir Coğrafi Bilgi Sistemleri projesinin olmamas1 sebebiyle çalışma sırasında ülke bazında örnek alınacak ve bu uygulama başka bir proje ile mukayese edilememiş ve kısıtlayıcı etkenlerden biri olmuştur. $\mathrm{Bu}$ nedenle bu konuda Coğrafi Bilgi Sistemleri ile beraber çözüm üreten projelerin arttırılması faydalı olacaktır. 
- Fiziksel engelli bir öğrenciyle/bireyle uygulama alanında gerçek durum değerlendirmesi yapılmasi ve sorunların tespit edilmesi daha gerçekçi olacaktır.

- Ülkemizde nadide bir konuma sahip olan üniversitemizin Beytepe Yerleşkesi'nin fiziki engeli olan insanların kolay ve güvenle ulaşılabilir ve kullanılabilir olması için TS 12576 "Şehir içi Yollar-Özürlü ve Yaşlılar için Sokak, Cadde, Meydan ve Yollarda Yapisal Önlemler ve ișaretlemelerin Tasarım Kuralları" ilkelerine uygun olarak yeniden düzenlenmesi gereklidir.

- Hem okulumuzda hem ülkemizde fiziksel engelli bireyler için CBS teknolojilerinin kullanılmasıyla ilgili çalışmalar yapılmalıdır.

\section{TEŞEKKÜR}

Hacettepe Üniversitesi Beytepe Kampüsü verilerinin alınmasında yardımcı olan Öğretim Görevlisi Ali Osman DEMİRER'e, çalışmamız sırasında yardımlarını eksik etmeyen Öğretim Görevlisi Dr. Engin TUNALI'ya, Ağ Analiz konusunda yardımeı olan Murat AKDOĞAN ve Umut ÜÇOK 'a teşekkürlerimzi sunarız.

\section{KAYNAKCA}

Bashiti, A. and Rahim, A., 2016, Physical Barriers Faced by People with Disabilities (PwDs) in Shopping Malls, Procedia - Social And Behavioral Sciences ,222, 414 - 422

Büke, C.O. ve Erturaç, M.K.,2016, Ağ Analiz Yöntemiyle Sakarya Üniversitesi Esentepe Kampüsünün İncelenmesi ve Web Tabanli Sunumu, Nature Sciences, 4A0053, 2016; 11(4): 14-25

Çivici, T. ve Gönen, D., 2015, Ballkesir Üniversitesi Çağış Yerleşkesinin Bedensel Engelli Öğrencilerin Sosyal Alanlara Ulaşabilirliğinin Değerlendirilmesi, Süleyman Demirel Üniversitesi Mühendislik Bilimleri ve Tasarım Dergisi, ISSN:1308-6693, 639-646

Eliöz, M., Demir, A., ve Akbuğa, E. Temmuz 2017, Engelli Dostu İller Sıralaması Çalışması, Akademik Sosyal Araştırmalar Dergisi, 50, 348-365
Enders, A. and Brandt, Z., 4/2007, Using Geographic Information System Technology to Improve Emergency Management and Disaster Response for People With Disabilities, Journal Of Disability Policy Studies, Vol. 17, 223-229

Esatbeyoğlu, F., Karahan, B.G., Engelli Bireylerin Fiziksel Aktiviteye Katılımlarının Önündeki Engeller, Spor Bilimleri Dergisi, 2014, 25 (2), 43-55.

Ferrari, L., Berlingerio ,M., Calabrese,F., Reades, J., 25 October 2013, Improving The Accessibility of Urban Transportation Networks For People With Disabilities, Transportation Research Part C, 27-40

Gray, J., M.P.P., Zimmerman,J., and Rimmer ,J., 5 2012, Built Environment Instruments for Walkability, Bikeability, And Recreation: Disability And Universal Design Relevant, Disability and Health Journal, 87-100

Iwarsson, S. and Sta, A., 07 Jul 2009, Accessibility, Usability And Universal Design Positioning And Definition Of Concepts Describing Person-Environment Relationships, Disability and Rehabilitation Taylor \& Francis Ltd ,ISSN 1464-5165 ,57-66

Kesik, O., Aydınoğlu, A. ve Taştan, B., 12.12.2015, A $\breve{g}$ Analizi Tekniklerini Kullanarak Afetlerle Başaçıkabilmede Erişebilirlik: İstanbul Fatih İlçesi Örneği, Doğu Coğrafya Dergisi, 36, 79-94

Kırtaş, H, A., Engelli Bireylerin Yangın Tahliyesinin Araştırılması, Yüksek Lisans Tezi, İzmir Katip Çelebi Üniversitesi, Fen Bilimleri Enstitüsü, A Agustos 2017

Mikušová, M., 2014, Sustainable Structure For The Quality Management Scheme To Support Mobility Of People with Disabilities, Procedia - Social and Behavioral Sciences, 160, $400-409$

Özkan, A., ve Yılmaz, M., April 2015, Yerleşkelerde Herkes İçin Tasarım Yaklaşımı: Hacettepe Üniversitesi Beytepe Yerleşkesi Deneyimi, Hacettepe Üniversitesi Güzel Sanatlar Fakültesi Yayınlarl, No: 47, ISBN 975-491-232-7, 51-60

Öztürk, S. ve İsmail, T., 2015, Kastamonu Kent Merkezinde Fiziksel Engelli Hareketliliği, Süleyman Demirel Üniversitesi Mühendislik Bilimleri ve Tasarım Dergisi, ISSN: 1308-6693, 511-516

Schlingensiepen, J., Naroska, E., Bolten,T., Christen,O., Schmitz,S. and . Ressel,C., 2015.07, Empowering People with Disabilities Using Urban Public Transport, Procedia Manufacturing, 2349 - 2356 
Sedlak, P., Komarkova, J., and Piverkova, A., January 2010, Spatial Analyses Help to Find Movement Barriers for Physically Impaired People in the City Environment, Wseas Transactions On Information Science And Applications, ISSN: 17900832, 122-131

Sirel, B., Boyacıgil, O., Duymuş, H., Konakl1, N., Altunkasa, F. ve Uslu, C., Haziran 2012 Çukurova Üniversitesi Yerleşkesi Açık Alanlarının Fiziksel Engelliler Bakımından Ulaşılabilirliğinin Değerlendirilmesi, Çukurova Üniversitesi Mühendislik Mimarlık Fakültesi Dergisi, 27(1), 53-72

Sze, N. and Christensen, K. , Access To Urban Transportation System For Individuals With Disabilities, 20 May 2017, IATSS Research, 66-73

Tandoğan, O., 2017, Evrensel Tasarım Kavramı ve Kentsel Peyzaj İle İlgili Örnekler Üzerinden Değerlendirilmesi, Artium, Cilt 5, Sayı 2, 51-66,

Tellioğlu, S. ve Şimşek, N., Kasım 2016, Dünyada ve Türkiye'de Engelli Dostu Turizm, Akademik Sosyal Araştırmalar Dergisi, 33, 552-567

True, E. ve Türel, H., 12.07.2013, Yapılı Çevrelerin Fiziksel Engelliler Yönüyle Kullanılabilirliği: İzmir Kenti Örneği, Artium, Sayı 1, Cilt 1, 1-16,

(URL-1)

http://www.worldbank.org/en/news/immers ive-story/2018/01/31/3-big-ideastoachieve-sustainable-cities-andcommunities. [Ziyaret Tarihi 31/01/2018]

(URL-2)

http://www.un.org/disabilities/documents/2 016/Urban/DESAissuepaperonAccessibilit yandInclusionofPersonswithDisabilitiesinU (URL-3) rbanDevelopment.pdf

https://www.dunya.com/kose-

yazisi/engelli-dostu-kent-mersin/389008,

(URL-4)

[Ziyaret Tarihi 01/11/2017]

http://www.kureselhedefler.org/hedefler/su rdurulebilir-sehir-ve-yasam-alanlari

(URL-5)

(URL-6)

https://unhabitat.org/un-habitat-at-a-glance/

http://habitat.csb.gov.tr/yeni-kentsel-

(URL-7)

gundem-new-urban-agenda-i-5733

http://uclg

mewa.org/uploads/file/f9961ba4033045049

b95efd366c26765/Yeni\%20Kentsel\%20g\%

C3\%BCndemTR.pdf
(URL-8)

https://acikders.ankara.edu.tr/pluginfile.php 19259/mod_resource/content/0/engelsiz\%C

(URL-9) 5\%9Fehirplanlama\%20raporu

https://engelsizbarinmaengelsizegitim.files wordpress.com/2013/09/mimari-tasarim-

(URL-10) v.pdf

https://prezi.com/_9w0hrzarxey/arcgisnetwork-analiz-egitimi/

(URL-11)

http://desktop.arcgis.com/en/arcmap/10.3/a nalyze/modelbuilder/what-ismodelbuilder.htm 